\title{
Effects of Morphology of Cerium Oxide Catalysts for Reverse Water Gas Shift Reaction
}

\author{
Marijana Kovacevic $^{1} \cdot$ Barbara L. Mojet $^{1} \cdot$ Jan G. van Ommen $^{1} \cdot$ Leon Lefferts $^{1}$
}

Received: 14 January 2016/Accepted: 19 January 2016/Published online: 20 February 2016

(C) The Author(s) 2016. This article is published with open access at Springerlink.com

\begin{abstract}
Reverse water gas shift reaction (RWGS) was investigated over cerium oxide catalysts of distinct morphologies: cubes, rods and particles. Catalysts were characterized by X-ray diffraction, Raman spectroscopy and temperature programmed reduction (TPR) in hydrogen. Nanoshapes with high concentration of oxygen vacancies contain less surface oxygen removable in TPR. Cerium oxide cubes exhibited two times higher activity per surface area as compared to rods and particles. Catalytic activity of these nanoshapes in RWGS reaction exhibited a relation with the lattice microstrain increase, however a causal relationship remained unclear. Results presented in this study suggest that superior catalytic activity of ceria cubes in RWGS originates from the greater inherent reactivity of (100) crystal planes enclosing cubes, contrary to less inherently reactive (111) facets exposed at rods and particles.
\end{abstract}

Electronic supplementary material The online version of this article (doi:10.1007/s10562-016-1697-6) contains supplementary material, which is available to authorized users.

Leon Lefferts

1.lefferts@utwente.nl

1 Catalytic Processes and Materials, Faculty of Science and Technology, MESA+ Institute for Nanotechnology, University of Twente, P.O. Box 217, 7500 AE Enschede, The Netherlands

\section{Graphical Abstract}

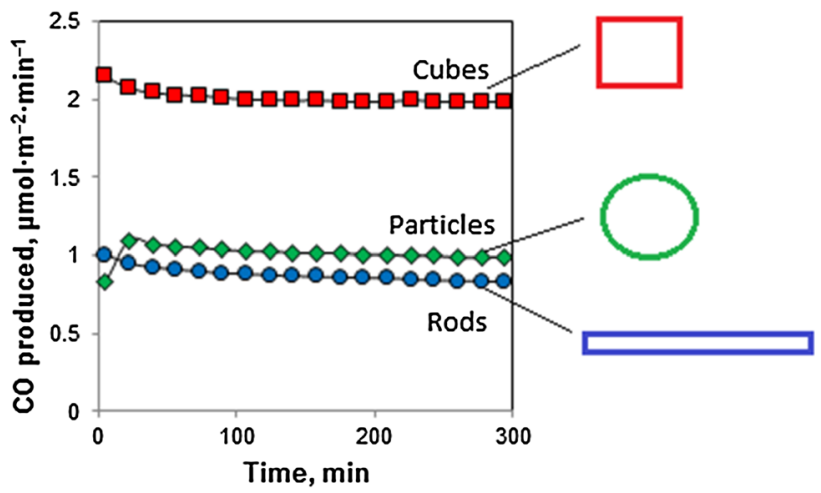

Keywords Reverse water gas shift - Ceria cubes - Rods . Particles

\section{Introduction}

Catalytic conversion of $\mathrm{CO}_{2}$ to $\mathrm{CO}$ via reverse water gas shift (RWGS) reaction is a promising alternative for $\mathrm{CO}_{2}$ utilization [1,2]. Water gas shift (WGS) and RWGS occur in all chemical processes when $\mathrm{CO}_{2}$ and $\mathrm{H}_{2}$, or $\mathrm{CO}$ and $\mathrm{H}_{2} \mathrm{O}$ coexist in a reaction mixture [2]. RWGS is reported to increase the desired product yield at equilibrium when coupled with dehydrogenation of hydrocarbons [3-5]. WGS is commonly used in combination with steam reforming of hydrocarbons aiming to maximise hydrogen yield [6-8]. It plays an vital role in Fisher-Tropsch synthesis, ammonia and methanol production. Two extensively discussed mechanisms in literature for (R)WGS are redox and associative formate decomposition [9]. Efficient 
catalysts have been designed for low and high temperature applications. However designing an robust and active catalyst that can operate in a single stage (R)WGS reactor still remains a challenge $[10,11]$.

Cerium oxide is widely employed in catalysis because of its unique oxygen storage capacity (OSC), the ability to reversibly store and release oxygen while formally switching between $\mathrm{Ce}^{4+}$ to $\mathrm{Ce}^{3+}$ in stable fluorite lattice [12]. The degree of the oxygen ion mobility in ceria lattice is associated with the size, dispersion and abundancy of oxygen vacancy defects [13-15]. Theoretically, oxygen vacancy formation and ability of the catalyst to act as oxygen donor-acceptor is related to the stability of particular crystal facets of the ceria surface [16, 17]. Although discrepancy in literature exist regarding exposed crystal planes at the surfaces of ceria rods, recent studies in our group demonstrated that stable (111) crystal planes are mainly exposed at the surface of both ceria rods and octahedra while ceria cubes are enclosed by mainly (100) crystal terminations [18]. Therefore, manipulation of catalyst shape is an approach for tuning the fraction of reactive crystal planes at the ceria surface and this is becoming a novel strategy in obtaining advanced catalytic materials with superior OSC and catalytic reactivity $[19,20]$.

Ceria nanocubes of average $10 \mathrm{~nm}$ size exhibit considerable OSC at a temperature as low as $150{ }^{\circ} \mathrm{C}$, that is for $250{ }^{\circ} \mathrm{C}$ lower than the temperature needed for cerium oxide particles of irregular shape to exhibit comparable OSC [21]. Enhanced OSC of cube and rod shaped ceria originate both from its surface and bulk structure [22].

Ceria nanoshapes have been investigated in e.g. $\mathrm{CO}$ oxidation [23-25], NO reduction [26] and WGS reaction [27]. Ceria nanorods exhibited superior activity in oxidation of $\mathrm{CO}, 1,2$-dichloroethane, ethyl-acetate and ethanol $[19,28-30]$, methanol conversion in presence of $\mathrm{CO}_{2}$ [31], methanol [32] and acetaldehyde decomposition [33] compared to ceria cubes and octahedra. Moreover, shuttleshaped particles composed of closely packed ceria nanorods displayed higher activity for $\mathrm{CO}$ oxidation compared to ceria nanorods [34], which has been attributed to enhanced porosity, surface area and oxygen deficiency of these nanoshapes compared to ceria rods. Ceria nanocubes on the other hand displayed greater activity compared to nanoparticles of irregular morphology in selective oxidation of toluene and benzene oxidation [35]. Pure and supported ceria nanocubes exhibited twice higher activity in oxidation of hydrogen and ethanol compared to rods and particles [36, 37]. Similar trends were reported by our group in WGS and ethylbenzene dehydrogenation $[18,38]$. In this study we report the effect of well-defined morphologies of $\mathrm{CeO}_{2}$ on catalytic activity during the RWGS reaction. To the best of our knowledge this has not been studied before.

\section{Experimental Part}

\subsection{Materials}

Commercially available $\mathrm{NaOH}$ pellets (Merck, 99\%), $\mathrm{Ce}\left(\mathrm{NO}_{3}\right)_{3} \cdot 6 \mathrm{H}_{2} \mathrm{O}\left(99.99 \%\right.$ Aldrich) and $\mathrm{Ce}(\mathrm{OH})_{4}$ (Merck, $99 \%)$ were used for catalyst synthesis.

\subsection{Catalyst Preparation}

Cerium oxide rods and cubes were prepared modifying the synthesis procedure reported elsewhere [25]. In the preparation of ceria rods $1.75 \mathrm{~g}$ of $\mathrm{Ce}\left(\mathrm{NO}_{3}\right)_{3} \cdot 6 \mathrm{H}_{2} \mathrm{O}$ was first dissolved in $11 \mathrm{ml}$ of distilled water. The solution was rapidly added to $73 \mathrm{ml}$ of 10 mass $\% \mathrm{NaOH}$ aqueous solution. In the preparation of ceria cubes mixing was performed vice versa: $\mathrm{NaOH}$ aqueous solution was rapidly added to previously dissolved $\mathrm{Ce}\left(\mathrm{NO}_{3}\right)_{4} \cdot 6 \mathrm{H}_{2} \mathrm{O}$ in distilled water. The resulting mixtures were stirred for $10 \mathrm{~min}$ (250 rpm), transferred into an autoclave $(125 \mathrm{ml})$ which was placed in an oven at $130{ }^{\circ} \mathrm{C}$ for $18 \mathrm{~h}$ and was allowed to cool to room temperature. Thus obtained precipitates were centrifuged at room temperature, rinsed with distilled water until $\mathrm{pH} 7$ was obtained and dried overnight at $110{ }^{\circ} \mathrm{C}$. Finally, the samples were calcined in flowing synthetic air at $650{ }^{\circ} \mathrm{C}$ for $5 \mathrm{~h}$. Irregularly shaped ceria catalyst was obtained by calcining commercial $\mathrm{Ce}(\mathrm{OH})_{4}$ under identical conditions.

\subsection{Catalyst Characterization}

Catalysts surface area (BET) was determined by $\mathrm{N}_{2}$-adsorption isotherm obtained at $77 \mathrm{~K}$ (Micromeritics Tristar). The samples were outgassed in vacuum at $200^{\circ} \mathrm{C}$ for $24 \mathrm{~h}$ prior to analysis.

Catalyst morphology was studied by Scanning Electron Microscopy, (SEM) LEO 1550 FEG-SEM equipped with in-lens detector. Transmission electronic microscopy (TEM) images were obtained on a Philips CM300ST-FEG electron microscope operated at an acceleration voltage of $300 \mathrm{kV}$. Samples for TEM measurements were ultrasonically dispersed in ethanol and subsequently droplets of the suspension were deposited on a copper grid coated with carbon.

$\mathrm{X}$-ray diffraction (XRD) was performed a using PANalytical X́pert-APD powder diffractometer equipped with a position sensitive detector analyses over the 20-range between $25^{\circ}$ and $65^{\circ}$ using $\mathrm{Cu} \mathrm{K}-\alpha$ radiation, $\lambda=0.1544 \mathrm{~nm}$. The average crystallite size was estimated using the Scherer equation assuming spherical particle geometry. We further used peak width analysis to estimate lattice microstrain employing the equation $[39,40]$ : 
$(\delta 2 \theta)^{2} / \tan ^{2} \theta_{0}=K \cdot \lambda /\left(D \cdot\left(\delta 2 \theta / \tan \theta_{0} \cdot \sin \theta_{0}+16 \varepsilon^{2}\right)\right)$,

where $\theta_{0}$ stands for the position of peak maximum, $\delta 2 \theta$ denotes FWHM in radians, $\mathrm{K}$ is a Scherrer constant that equals 0.9 assuming spherical grains, $\lambda$ is the $\mathrm{X}$-ray wavelength and $\mathrm{D}$ and $\varepsilon$ represent the average grain size and the lattice microstrain, respectively. By plotting $(\delta 2 \theta)^{2} / \tan ^{2} \theta_{0}$ versus $\delta 2 \theta / \tan \theta \cdot \sin \theta$ for several diffraction peaks, $\mathrm{K} \cdot \lambda / \mathrm{D}$ can be calculated from the slope, allowing determination of the crystallite size, while microstrain values can be extracted from the ordinate intercept which equals $16 \varepsilon^{2}$. Scherrer's equation can be derived from Eq. 1 assuming that physical origin of the XRD peak broadening is due to the small grain size exclusively, neglecting any broadening caused by the strain accumulated in the lattice.

Raman spectroscopy measurements were performed with a Senterra Bruker instrument, equipped with a cooled CCD detector. The spectra were recorded at $\lambda=532 \mathrm{~nm}$, with $2 \mathrm{~s}$ integration time and 20 co-additions, $10 \mathrm{~mW}$ laser power and at a resolution of $9-15 \mathrm{~cm}^{-1}$. Spectra were measured ex-situ at room temperature in ambient air on as prepared catalysts (calcined and cooled to room temperature slowly in flowing air).

Temperature programmed reduction was performed in $5 \% \mathrm{H}_{2}$ in He with a heating ramp of $5{ }^{\circ} \mathrm{C} \mathrm{min}^{-1}$ from 30 to $600{ }^{\circ} \mathrm{C} .50 \mathrm{mg}$ of the catalyst was pre-treated at $450{ }^{\circ} \mathrm{C}$ in oxygen for $60 \mathrm{~min}$ prior to analysis. Signals were recorder using TCD detector. Water has been removed using cold trap.

\subsection{Catalytic Testing}

The catalytic tests were performed at atmospheric pressure and isothermal conditions $\left(560{ }^{\circ} \mathrm{C}\right)$ in a fixed-bed quartz tubular reactor $\left(4.0 \mathrm{~mm}\right.$ i.d.). The tests were carried out in $3 \% \mathrm{H}_{2}$, $37 \% \mathrm{CO}_{2}$ balance $\mathrm{N}_{2}$, in a total flow of $30 \mathrm{ml} \mathrm{min}^{-1}$. Prior to reaction, catalysts were pretreated in pure $\mathrm{N}_{2}$ at $580{ }^{\circ} \mathrm{C}$ (30 min) and consequently in pure $\mathrm{CO}_{2}$ at the reaction temperature $(30 \mathrm{~min})$. The amount of catalyst per run was tuned in such a way that $\mathrm{CO}_{2}$ conversion was kept below $5 \%$, ensuring differential experiments. Reaction products were analyzed by on-line GC Varian-450 equipped with TCD and FID detector and four columns: Hayesep T, Hayesep Q, Molsieve 13X and CP-Wax. The experiments were reproducible with a typical overall error in the carbon mass balance smaller than $5 \%$.

\section{Results and Discussion}

\subsection{Catalysts Synthesis and Characterization}

Figure 1 shows the high resolution scanning electron microscopy (HRSEM) images of ceria catalysts obtained by three different routes: ceria rods (a), cubes (b) and particles (c). TEM images of these ceria nanoshapes clearly confirm distinct crystallite shape and morphology of these samples (Supporting information, Figure SI1) [38].

In this study ceria cubes were obtained at lower temperature and lower $\mathrm{OH}^{-}$conc. $\left(2 \mathrm{~mol}^{-1}\right)$ than commonly reported in literature $\left(6 \mathrm{~mol}^{-1}\right)$ [22, 41]. Several studies indicated that when both temperature and $\mathrm{OH}^{-}$concentration are low $\left(100{ }^{\circ} \mathrm{C}, \mathrm{C}_{\mathrm{NaOH}}<1 \mathrm{~mol} \mathrm{l}^{-1}\right)$ isotropic growth of $\mathrm{Ce}(\mathrm{OH})_{3}$ nuclei proceeds resulting in ceria polyhedra formation [41-43]. However, at $\mathrm{OH}^{-}$concentration above $1 \mathrm{~mol} \mathrm{l}^{-1}$ dissolution/ recrystallization is significant and anisotropic growth of $\mathrm{Ce}(\mathrm{OH})_{3}$ nuclei is leading formation of rods, unless $\mathrm{Ce}(\mathrm{OH})_{3}$ intermediate decomposes at higher temperatures $\left(180^{\circ} \mathrm{C}\right)$ resulting in formation of cubes [22, 41-43]. Apparently the temperature of the hydrothermal treatment of $130{ }^{\circ} \mathrm{C}$ in this study was sufficient to induce $\mathrm{Ce}(\mathrm{OH})_{3}$ decomposition and consequently formation of ceria cubes. In this way, morphology of ceria can be controlled, even in absence of modifiers such as ethylenediamine inducing anisotropic crystal growth [44].

Table 1 shows the BET surface areas as determined by nitrogen physisorption, revealing decreasing surface area from rods to cubes and finally particles (Table 1).

Catalyst structure was further investigated by XRD. Dominant Bragg diffractions were observed at $28.8^{\circ}, 47.6^{\circ}$ and $56.7^{\circ} 2 \theta$, corresponding to respectively (111), (220) and (311) crystal planes of the fluorite fcc structure of $\mathrm{CeO}_{2}$ (Fig. 2) [45]. The average crystallite size as determined by the Scherrer equation and Eq. 1, including microstrain, increased in the order: cubes $<$ rods $<$ particles. These two methods result in identical numbers, considering the experimental error, indicating that peak broadening is dominated by the particle size effect over any effect of micro-strain. Calculated crystallite size of ceria particles is consistent with the particle diameter deduced based on SEM images (Table 1, column c). Ceria rods have a width of about $10 \mathrm{~nm}$ and average length of $160 \mathrm{~nm}$ (Fig. 1a) while the size estimated by XRD results in a value in between (Table 1). Average crystallite size of ceria cubes deduced from SEM images is $37 \mathrm{~nm}$ (Fig. 1b), which is significantly higher compared to XRD estimate of $18 \mathrm{~nm}$ (Fig. 1b; Table 1). Similar discrepancies in literature in case of ceria cubes were assigned to the broad crystallite size distribution, which is also evident in Fig. 1b [46]. The assumption that crystallites have spherical geometry also contributes to this discrepancy.

Interestingly, lattice microstrain is significantly higher in cubes than in rods and particles (Table 1). Lattice microstrain is known to be associated with lattice expansion caused by increasing content of oxygen vacancies in the fluorite lattice [47]. Theoretical studies predicted decreasing energy of oxygen vacancy formation with 

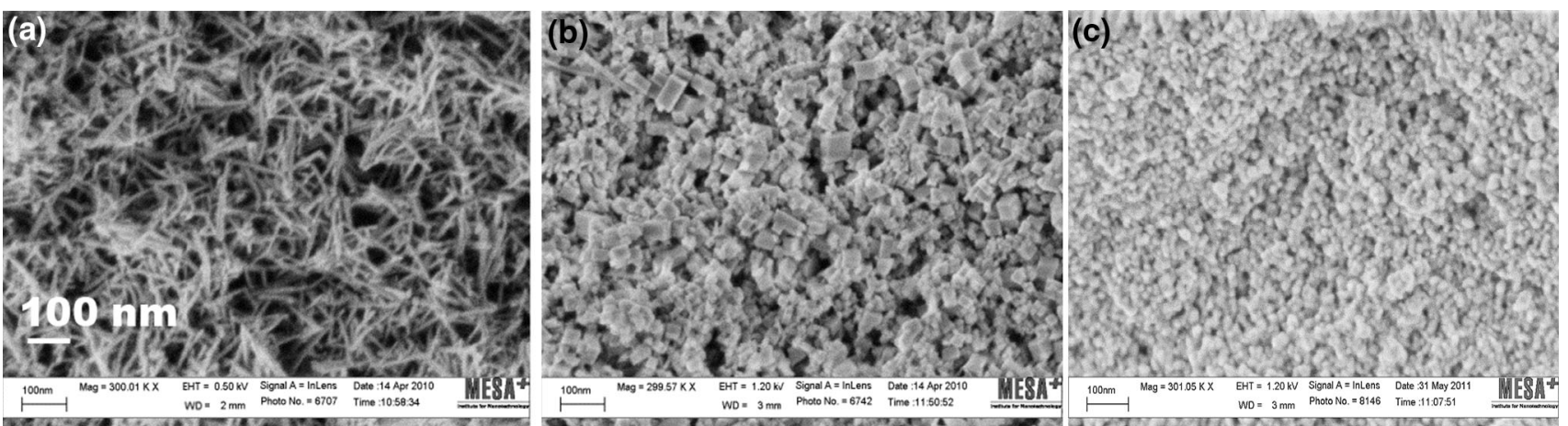

Fig. 1 HRSEM images of ceria rods (a), cubes (b) and particles (c) [38]

Table 1 Catalysts structural and textural properties according $\mathrm{N}_{2}$-physisorption, XRD and SEM; particle size calculated based on: Scherrer equation (a), Eq. 1 including lattice microstrain (b) and SEM images (c) and lattice microstrain for ceria rods, cubes and particles

\begin{tabular}{lllllll}
\hline $\begin{array}{l}\text { Ceria } \\
\text { morphology }\end{array}$ & $\begin{array}{l}\text { BET surface } \\
\text { area }\left(\mathrm{m}^{2} / \mathrm{g}\right)\end{array}$ & $\begin{array}{l}\text { Crystallite size, } \\
\text { Scherer eq., d } \\
(\mathrm{nm})^{\mathrm{a}}\end{array}$ & $\begin{array}{l}\text { Crystallite size, Eq 1 } \\
\text { including microstrain, d } \\
(\mathrm{nm})^{\mathrm{b}}\end{array}$ & $\begin{array}{l}\text { Crystallite size, } \\
\text { SEM images, d } \\
(\mathrm{nm})^{\mathrm{c}}\end{array}$ & $\begin{array}{l}\text { Width particle-size } \\
\text { distribution, SEM } \\
\text { images } \\
(\mathrm{nm})^{\mathrm{c}}\end{array}$ & $\begin{array}{l}\text { Lattice } \\
\text { microstrain, } \\
\varepsilon,(\%)\end{array}$ \\
\hline Rods & $73 \pm 4$ & $24 \pm 1$ & $25 \pm 2$ & $10^{*}$ & 4 & $0.08 \pm 0.008$ \\
Cubes & $37 \pm 2$ & $18 \pm 1$ & $19 \pm 2$ & 37 & 20 & $0.15 \pm 0.02$ \\
Particles & $24 \pm 1$ & $30 \pm 1$ & $30 \pm 3$ & 26 & $6.08 \pm 0.008$ \\
\hline
\end{tabular}

* Denotes the width of ceria rods corresponding to the average length of $160 \mathrm{~nm}$

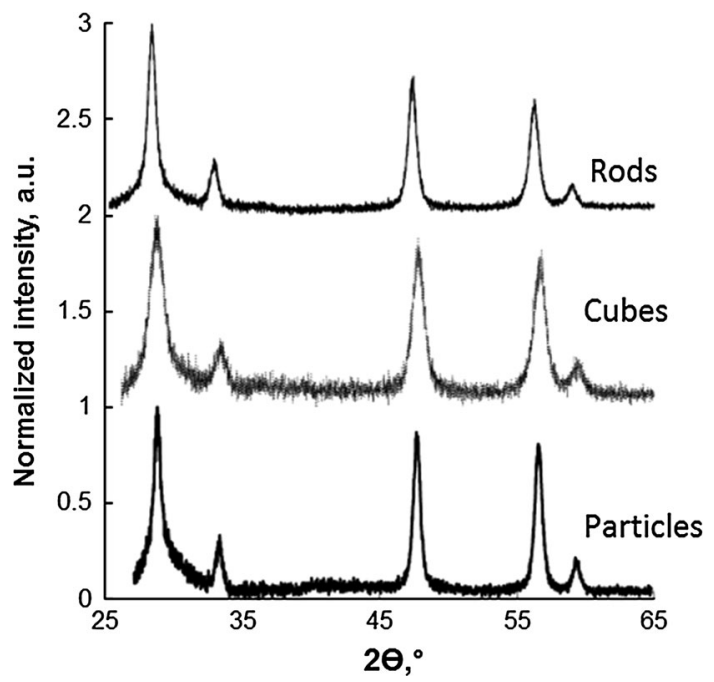

Fig. 2 XRD patterns for rods, cubes and particles

increasing lattice microstrain [48]. Raman spectroscopy was therefore used to characterize the oxygen vacancy abundances. Figure 3a shows the Raman spectra of fresh ceria catalysts, as prepared. The spectra are dominated by a strong peak at $464 \mathrm{~cm}^{-1}$ from the $\mathrm{F}_{2} \mathrm{~g}$ mode of the $\mathrm{CeO}_{2}$ fluorite lattice, in agreement with the XRD patterns (Fig. 2) [46]. Two weaker bands identified are assigned to oxygen displacement $\left(258 \mathrm{~cm}^{-1}\right)$ and oxygen vacancies $\left(600 \mathrm{~cm}^{-1}\right)$ [46, 49].

As presented in Fig. 3b, the intensities of oxygen displacement and oxygen vacancy bands are the highest for ceria rods, followed by ceria cubes and particles. These trends are further in agreement with the increasing broadening of the $464 \mathrm{~cm}^{-1}$ band in the order: particles $<$ cubes $<$ rods (Fig. $3 b$ ). Similar observation has been reported for ceria nanowires [50] and related to disorder in oxygen sub-lattice due to thermal and/ or grain size induced non-stoichiometry originating from combined effects of lattice strain and phonon confinement [51-53]. In this study however we observed no relation between the lattice microstrain (Table 1) and Raman $464 \mathrm{~cm}^{-1}$ band broadening of these ceria samples (Fig. 3).

Hydrogen temperature programmed reduction $\left(\mathrm{H}_{2}-\mathrm{TPR}\right)$ was further used to study the reducibility of these ceria nanoshapes. TPR profiles of ceria particles (Fig. 4) reveal a minor reduction peak at $210{ }^{\circ} \mathrm{C}$ and the main reduction peak at about $487{ }^{\circ} \mathrm{C}$, while ceria cubes and rods have broad reduction peaks with maxima at 425 and $560{ }^{\circ} \mathrm{C}$. Peaks below $600{ }^{\circ} \mathrm{C}$ are assigned to consumption of surface oxygen [54], in contrast to reduction peaks above $800{ }^{\circ} \mathrm{C}$ would indicate bulk reduction of $\mathrm{CeO}_{2}$ to $\mathrm{Ce}_{2} \mathrm{O}_{3}$ [55]. 
Fig. 3 Full Raman spectra of ceria rods, cubes and particles (a); oxygen displacement $\left(258 \mathrm{~cm}^{-1}\right)$ and oxygen vacancy $\left(600 \mathrm{~cm}^{-1}\right)$ vibration bands for ceria rods, cubes and particles (b). The spectra are normalized on the intensity of the main peak at $464 \mathrm{~cm}^{-1}$

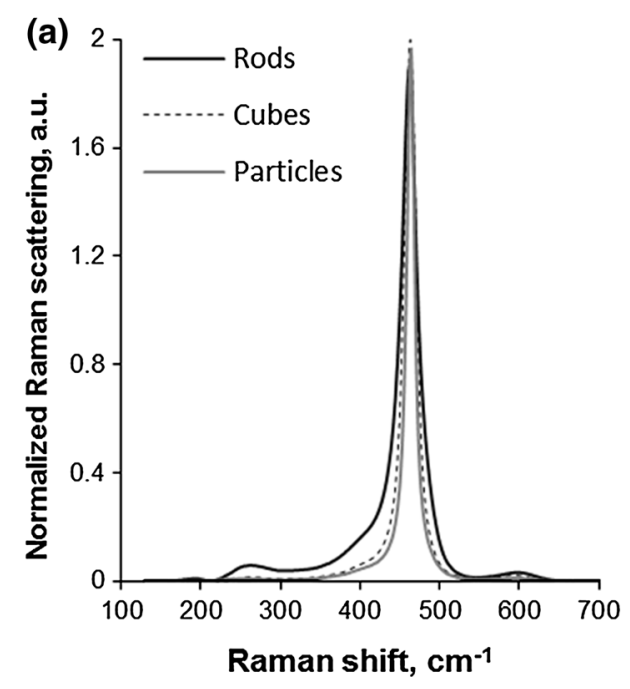

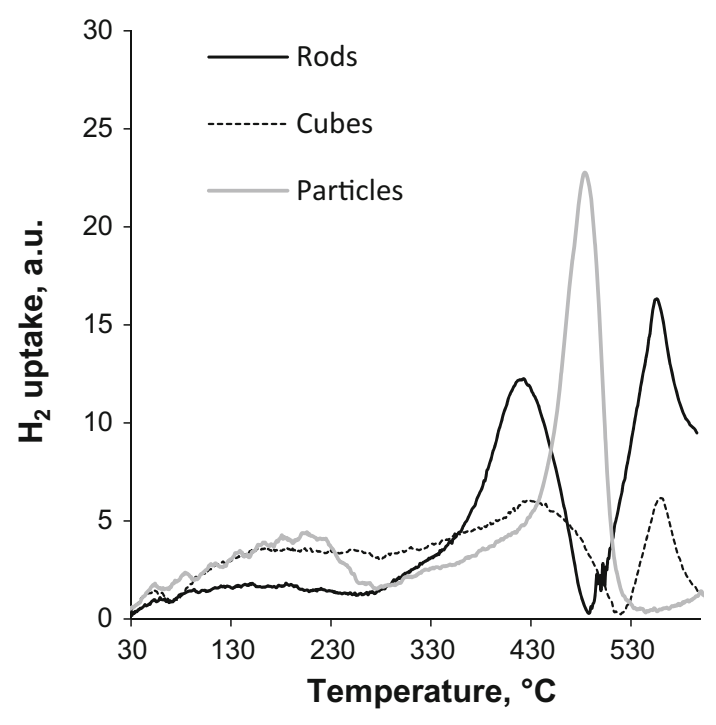

Fig. $4 \mathrm{H}_{2}$-TPR results for ceria rods, cubes and particles

Total amount of oxygen consumed expressed per catalysts surface area, per gram and monolayer capacity (ML) is presented in Table 2 .

When normalized per surface area overall reducibility of these catalysts decreases from ceria particles to cubes and finally rods (Table 2). The amount of consumed oxygen species is below one monolayer for all the investigated catalysts (Table 2).

\subsection{Catalytic Testing Results in RWGS Reaction}

Catalytic activity of the ceria catalysts was investigated in RWGS reaction at $560{ }^{\circ} \mathrm{C}$. Figure 5 compares catalytic activities of ceria cubes, rods and particles expressed as the amount of $\mathrm{CO}$ produced per gram of ceria (Fig. 5a) and per $\mathrm{m}^{2}$ (Fig. 5b). Ceria cubes are the most active compared to

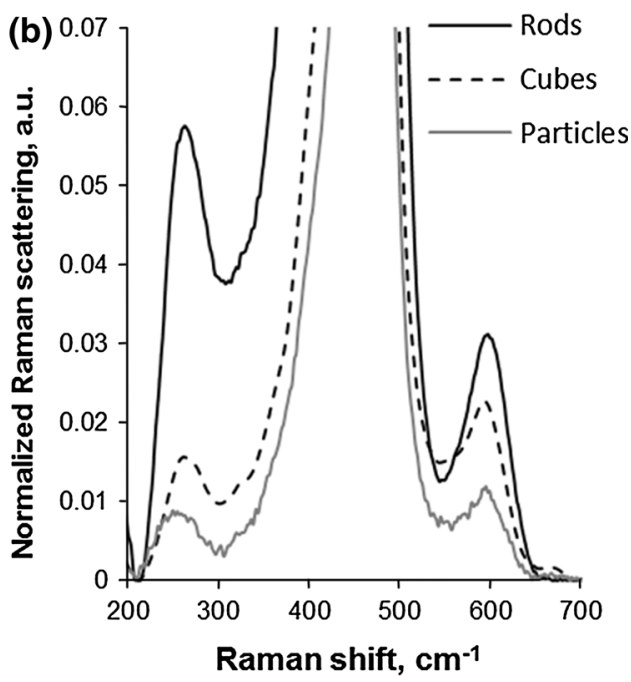

the other two morphologies, both per gram and per $\mathrm{m}^{2}$. Catalytic activity of ceria rods is slightly lower per gram compared to cubes and about two times lower per $\mathrm{m}^{2}$. Ceria particles show about two times lower activity compared to cubes both per gram and per $\mathrm{m}^{2}$. Minor deactivation was observed in all cases.

\subsection{Discussion}

Oxygen vacancy abundances in these ceria catalysts decrease in the order: rods $>$ cubes $>$ particles (Fig. 3b), consistent with results in literature revealing higher intrinsic oxygen deficiency in ceria rods compared to cubes and octahedra [46]. It is reasonable to assume that bulk oxygen deficiency induces oxygen deficiency at the surface of these nanoshapes. TPR shows that reduction below $600{ }^{\circ} \mathrm{C}$ results in removal of oxygen in sub-monolayer amounts (Table 2), which is well in agreement with the claim that only surface oxygen is involved [54] when reducing ceria below $600{ }^{\circ} \mathrm{C}$. Comparison of Raman spectroscopy and TPR results confirm that catalysts with higher abundancy of oxygen vacancies according Raman spectroscopy (rods $>$ cubes $>$ particles) indeed contain less reducible surface oxygen species (rods $<$ cubes $<$ particles, Table 2).

Ceria cubes contain more lattice microstrain compared to rods and particles (Table 1). Increasing lattice microstrain is reported to enhance oxygen ion diffusivity and OSC of ceria [56] and $\mathrm{Ce}_{1-\mathrm{x}} \mathrm{Zr}_{\mathrm{x}} \mathrm{O}_{2}$ nanoparticles, respectively [57]. Hence, it would be expected that ceria cubes exhibit higher reducibility compared to rods and particles. We however observed no relation between the overall catalysts reducibility in hydrogen (Table 2) and lattice microstrain in ceria nanoshapes (Table 1). This further supports the suggestion that the low temperatures (below $600^{\circ} \mathrm{C}$ ) 
Table 2 The overall amount of oxygen consumed in $\mathrm{H}_{2}$-TPR normalized per $\mathrm{m}^{2}$, gram and expressed as theoretical monolayer capacity (ML) on ceria rods, cubes and particles

\begin{tabular}{llll}
\hline Ceria morphology & $\mu \mathrm{mol} \mathrm{m}^{-2}$ & $\mu \mathrm{mol} \mathrm{g}^{-1}$ & ${\text { Monolayer capacity }(\mathrm{ML})^{\mathrm{a}}}^{\text {Rods }}$ \\
\hline Cubes & $1.1 \pm 0.05$ & $81 \pm 4$ & 0.19 \\
Particles & $1.8 \pm 0.1$ & $63 \pm 3$ & 0.29 \\
\hline
\end{tabular}

${ }^{a}$ The amount of consumed surface oxygen species versus theoretical monolayer capacity (ML) $[\mu \mathrm{mol} / \mu \mathrm{mol}]$

Fig. 5 Catalytic activity of ceria rods, cubes and particles expressed as the rate of $\mathrm{CO}$ production per $\mathrm{g}(\mathbf{a})$ and $\mathrm{m}^{2}(\mathbf{b})$ (a)

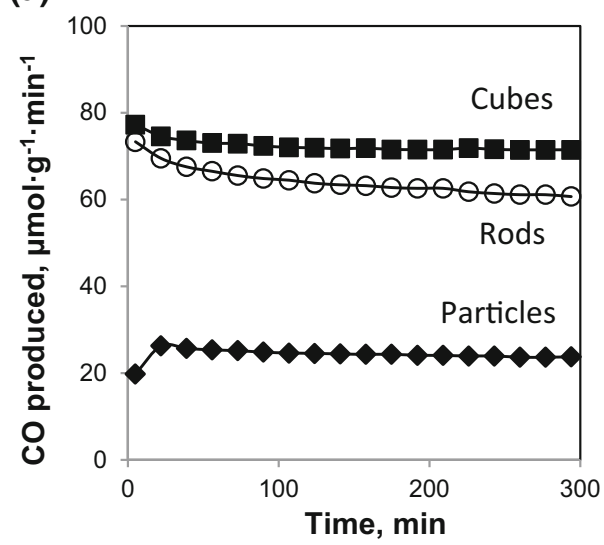

(b)

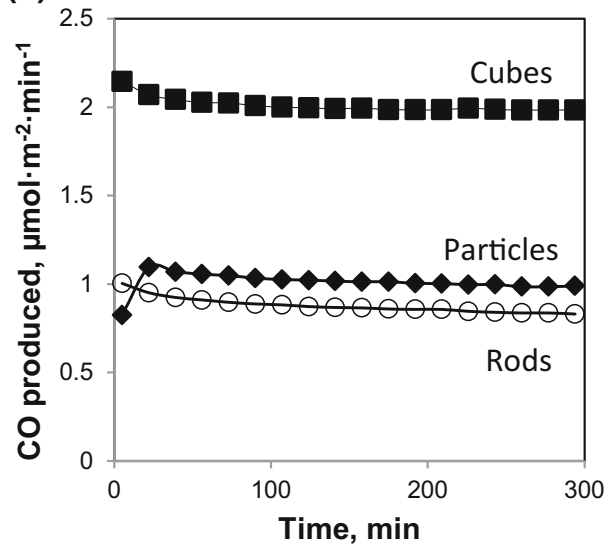

reduction in $\mathrm{H}_{2}$ causes removal of exclusively surface oxygen.

Catalysts were characterized under identical conditions and tested under identical conditions, allowing searching for correlations between structural properties and corresponding catalytic activity in RWGS. Increasing lattice microstrain (Table 1) seemingly correlates with the observed catalytic activity of these nanoshapes in RWGS (Fig. 5b); cubes are more active per surface area and contain clearly higher microstrain. Similar correlations between lattice microstrain and catalytic activity for $\mathrm{CO}$ oxidation and WGS have been reported for doped ceria nanoparticles of irregular morphology $[58,59]$ and supported ceria nanoshapes [27]. Theoretical simulations predicted increasing catalytic activity of ceria nanorods in $\mathrm{CO}$ oxidation with increasing lattice microstrain [60]. It has been suggested that increasing microstrain enhances active metal-ceria support interaction, resulting in improved dispersion of the active phase, stabilization of the active metal species in a lower valence state and enhanced overall reducibility [27, 61]. Supported ceria cubes were moreover reported to possess lower lattice microstrain and corresponding lower catalytic activity in WGS compared to rods [27]. This has been attributed to low stability of (100) crystal planes enclosing cubes compared to relatively more stable (111) surface terminations of rods. Stable catalytic performance of ceria cubes in RWGS (Fig. 4) suggests that the cubic shape and surface termination are stable under reaction conditions in this study.

For detailed identification of the exposed crystal facets for the three studied ceria nanoshapes, we refer to work previously reported by our group [18]. AC-HRTEM studies providing sub-angstrom resolution [22, 24], clearly revealed (111) crystal planes exposed at ceria rods and particles $[25,31,62,63]$, whereas ceria cubes are enclosed by mainly (100) facets [18]. These ceria nanoshapes exhibited exactly the same trends in activity per surface area for WGS reaction (decreasing from ceria cubes to rods and finally particles) as reported in this study on RWGS reaction (Fig. 5b) [18]. This result is expected based on the principle of the microscopic reversibility [18]. WGS has been suggested in literature to proceed via active hydroxyl species $(-\mathrm{OH})$ on the ceria surface [64]. The observed correlation between lattice micro-strain (Table 1) and catalytic activity in (R)WGS (Fig. 5b) hence might originate from increased reactivity of reactive $-\mathrm{OH}$ species and/or other surface intermediates on the strained ceria surfaces. However, this is clearly not supported by theoretical calculations, predicting that lattice microstrain has no effect on the reactivity of hydroxyl species terminating ceria surface [48]. Ceria cubes, exposing (100) facets, exhibit distinct $-\mathrm{OH}$ bands with discrete interaction with $\mathrm{CO}$, 
compared to rods and octahedra, resulting in enhanced reactivity in WGS, as reported by our group [18].

The order of the catalytic activity: cubes $>$ rods $\sim$ particles (Fig. 5b) is moreover consistent with the results reported for oxidation of hydrogen and ethanol over pure and supported ceria nanoshapes [36, 37]. Fundamental studies in addition revealed higher inherent reactivity of (100) crystal planes of ceria for methanol [65], water [66], acetaldehyde [67] and acetic acid [68] compared to (111) facets, though under very different conditions compared to realistic reaction conditions. This has been attributed to the lower coordination numbers in (100) facets, inducing higher reactivity of both cerium and oxygen at (100) ceria surfaces compared to (111) facets [69]. Results presented in this study suggest that higher reactivity of ceria cubes in RWGS is due to the superior inherent reactivity of (100) crystal planes enclosing cubes, contrary to less inherently reactive (111) facets enclosing rods and particles in RWGS. Although catalytic activity apparently correlates with the lattice micro-strain, it remains unclear whether this relationship is causal. Lattice micro-strain might well be a consequence of the specific crystal structure including the surface termination, instead of cause of the observed prominent activity of ceria cubes compared to rods and particles in RWGS.

\section{Conclusion}

Cerium oxide catalysts of distinct morphology, i.e. cubes, rods and particles of irregular shape, were characterized and investigated for RWGS. The nano-shapes as prepared differ in bulk-defect-concentration; high defect concentrations induce high concentrations of oxygen vacancies in the surface as evidenced by low amount of oxygen that can be removed from the surface via reduction. Catalytic testing under differential conversion of $\mathrm{CO}_{2}$ revealed superior catalytic activity of ceria cubes per $\mathrm{m}^{2}$ as compared to rods and particles. Catalytic activity of these catalysts in RWGS reaction exhibited an apparent correlation with lattice microstrain, however any causal relationship remains unclear. Results presented in this study suggest that superior catalytic activity of ceria cubes in RWGS in caused by highly inherently reactive (100) facets exposed at cubes compared to relatively inert (111) crystal planes enclosing rods and particles.

Acknowledgments This work was performed under the auspices of NIOK, the Netherlands Institute of Catalysis Research. Financial support of ASPECT Project No. 05362021 is greatly acknowledged. We thank to Ing. L. Vrielink for BET measurements and Drs. M. Smithers for HRSEM measurements. Technical support of Ing. B. Geerdink and K. Altena is highly appreciated.
Open Access This article is distributed under the terms of the Creative Commons Attribution 4.0 International License (http://crea tivecommons.org/licenses/by/4.0/), which permits unrestricted use, distribution, and reproduction in any medium, provided you give appropriate credit to the original author(s) and the source, provide a link to the Creative Commons license, and indicate if changes were made.

\section{References}

1. Xiaoding X, Moulijn JA (1996) Energy Fuels 10:305

2. Wang W, Wang S, Ma X, Gong J (2011) Chem Soc Rev 40:3703

3. Towler G, Lynn S (1994) Chem Eng Sci 49:2585

4. Park SE, Han SC (2004) J Ind Eng Chem 10:1257

5. Ansary MB, Park SE (2012) Energy Environ Sci 5:9419

6. Newsome DS (1980) Catal Rev 21:275

7. Moon D (2008) Catal Surv Asia 12:188

8. Ruettinger W, Ilinich O, Farrauto RJ (2003) J Power Sources 118:61

9. Rhodes C, Hutchings GJ, Ward AM (1995) Catal Today 23:43

10. Tabakova T, Idakiev V, Andreeva D, Mitov I (2000) Appl Catal A 202:91

11. Navarro RM, Pena MA, Fierro JLG (2007) Chem Rev 107:3952

12. Trovarelli A (1996) Catal Rev Sci Eng 38:439

13. Zhang CJ, Michaelides A, King DA, Jenkins SJ (2009) Phys Rev B 79:75433

14. Babu S, Thanneeru R, Inerbaev T, Day R, Masunov AE, Schulte A, Seal S (2009) Nanotechnology 20:85713

15. Ganduglia-Pirovano MV, Hofmann A, Sauer J (2007) Surf Sci Rep 62:219

16. Sayle TXT, Parker SC, Sayle DC (2005) Phys Chem Chem Phys 7:2936

17. van Bokhoven JA (2009) ChemCatChem 1:363

18. Agarwal S, Lefferts L, Mojet BL, Ligthart DAE, Hensen EJM, Mitchell DRG, Erasmus WJ, Anderson BG, Olivier EJ, Neethling JH, Datye AK (2013) ChemSusChem 6:1898

19. Zhou K, Li Y (2012) Angew Chem Int Ed 51:602

20. Sun C, Li H, Chen L (2012) Energy Environ Sci 5:8475

21. Zhang J, Kumagai H, Yamamura K, Ohara S, Takami S, Morikawa A, Shinjoh H, Kaneko K, Adschiri T, Suda A (2011) Nano Lett 11:361

22. Mai HX, Sun LD, Zhang YW, Si R, Feng W, Zhang HP, Liu HC, Yan CH (2005) J Phys Chem B 109:24380

23. Tana, Zhang M, Li J, Li H, Shen W (2009) Catal Today 148:179

24. Zhou K, Wang X, Sun X, Peng Q, Li Y (2005) J Catal 229:206

25. Liu X, Zhou K, Wang L, Wang B, Li Y (2009) J Am Chem Soc 131:3140

26. Liu L, Cao Y, Sun W, Yao Z, Liu B, Gao F, Dong L (2011) Catal Today 175:48

27. Si R, Flytzani-Stephanopoulos M (2007) Angew Chem Int Ed 47:2884

28. Wu Z, Li M, Overbury SH (2012) J Catal 285:61

29. Dai Q, Huang H, Zhu Y, Deng W, Bai S, Wang X, Lu G (2012) Appl Catal B 117-118:360

30. Li M, Wu Z, Overbury SH (2013) J Catal 306:164

31. Wang S, Zhao L, Wang W, Zhao Y, Zhang G, Ma X, Gong J (2013) Nanoscale 5:5582

32. Wu Z, Li M, Mullins DR, Overbury SH (2012) ACS Catal 2:2224

33. Mann AKP, Wu Z, Calaza FC, Overbury SH (2014) ACS Catal 4:2437

34. Sun C, Chen L (2009) Eur. J. Inorg. Chem. 3883

35. Lv J, Shen Y, Peng L, Guo X, Ding W (2010) Chem Commun 46:5909 
36. Dasaunay T, Bonura G, Chiodo V, Freni S, Couzinie JP, Bourgon J, Ringuede A, Labat F, Adamo C, Cassir M (2013) J Catal 297:193

37. Li H, Qi G, Tana Zhang X, Li W, Shen W (2011) Catal Sci Technol 1:1677

38. Kovacevic M, Agarwal S, Mojet BL, van Ommen JG, Lefferts L (2015) Appl Catal A 505:354

39. Nalwa HS (1999) Handbook of nanostructured materials and nanotechnology. Academic Press, San Diego

40. Tellkamp VL, Lau ML, Fabel A, Lavernia EJ (1997) Nonostruct Mater 9:489

41. Yuan Q, Duan HH, Li LL, Sun LD, Zhang YW, Yan CH (2009) J Colloid Interface Sci 335:151

42. Hirano M, Kato E (1996) J Am Ceram Soc 79:777

43. Hirano M, Kato E (1999) J Am Ceram Soc 82:786

44. Sun C, Li H, Zhang H, Wang Z, Chen L (2005) Nanotechnology $16: 1454$

45. Meriani S, Spinolo S (1987) Powder Diffr 2:255

46. Wu Z, Li M, Howe J, Meyer HM, Overbury SH (2010) Langmuir 26:16595

47. She Y, Zheng Q, Li L, Zhan Y, Chen C, Zheng Y, Lin X (2009) Int J Hydrogen Energy 34:8929

48. Maa Lub Z, Tangc Y, Lia T, Tanga Z, Yangb Z (2014) Phys Lett A 37:82570

49. McBride JR, Hass KC, Poindexter BD, Weber WH (1994) J Appl Phys 76:2435

50. Sun C, Li H, Wang ZX, Chen L, Huang X (2004) Chem Lett 33:622

51. Weber WH, Hass KC, McBride JR (1993) Phys Rev B 48:178

52. Kosacki I, Suzuki T, Anderson HU, Colomban P (2002) Solid State Ionics 149:99
53. Spanier JE, Robinson RD, Zhang F, Chan SW, Herman IP (2001) Phys Rev B 64:245407

54. Ranga Rao G (1999) Bull Mater Sci 22:89

55. Shyu JZ, Otto K (1989) J Catal 115:16

56. Rushton MJ, Chroneos A (2014) Sci Rep 4:6068

57. Si R, Zhang YW, Li SJ, Li BX, Yan CH (2004) J Phys Chem B 108:12481

58. Lei L, Ying-Ying Z, Chong-Qi C, Yu-Sheng S, Xing-Yi L, Qi Z (2009) Acta Phys Chim Sin 25:1397

59. Sudarsanam P, Mallesham B, Durgasri DN, Reddy BM (2014) RSC Adv 4:11322

60. Sayle TXT, Cantoni M, Bhatta UM, Parker SC, Hall SR, Mobus G, Molinari M, Reid D, Seal S, Sayle DC (2012) Chem Mater 24:1811

61. Yao SY, Xu WQ, Johnston-Peck AC, Zhao FZ, Liu ZY, Luo S, Sensanayke SD, Martinez-Arias A, Liu WJ, Rodriguez JA (2014) Phys Chem Chem Phys 16:17183

62. Ta N, Liu JJ, Chena S, Grozier PA, Li Y, Chen A, Shen W (2012) J Am Chem Soc 134:20585

63. Lawrence NJ, Brewer JR, Wang L, Wu T-S, Wells-Kingsbury J, Ihrig MM, Wang G, Soo YL, Mei W-N, Cheung CL (2011) Nano Lett 11:2666

64. Azzam KG, Babich IV, Seshan K, Leffers L (2007) J Catal 251:153

65. Mullins DR, Albrecht PM (2013) Langmuir 29:4559

66. Molinari M, Parker SC, Sayle DC, Islam MS (2012) J Phys Chem C 116:7073

67. Mullins DR, Albrecht PM (2013) J Phys Chem C 117:14692

68. Mullins DR, Albrecht PM, Calaza F (2013) Top Catal 56:1345

69. Mann AKP, Wu Z, Overbury SH (2015) Catalysis by materials with well-defined structures. Elsevier, Amsterdam, p 71 